\title{
„die ganze gesellschaftliche Welt in einer Nuß“ Opernhelden und ihr Publikum am Beispiel des deutschen Hoftheaters im mittleren 19. Jahrhundert
}

\section{Carolin Babr}

Die Geschichte der Oper ist eng mit der Geschichte der Gesellschaft und ihres Wandels verknüpft. Doch was in der musik- und kulturwissenschaftlichen Forschung als unbestrittene Tatsache gilt, erweist sich als problematisch, sobald konkrete Wechselbeziehungen zwischen Oper und Gesellschaft aufgezeigt und beschrieben werden sollen. Die Frage danach, ob Opern (sowie auch die darstellenden Künste im Allgemeinen) einen direkten Einfluss auf gesellschaftliche Entwicklungen haben und vice versa, wird in gegenwärtigen Untersuchungen kontrovers und eingehend diskutiert. ${ }^{1}$ Dabei ist es dem wissenschaftlichen Paradigmenwechsel der 1960er Jahre und der zunehmenden Betonung der performativen Zusammenhänge dramatischer Texte zu verdanken, dass auch Opern nicht mehr nur in ihrer fixierten, unveränderbaren Werkgestalt untersucht werden, sondern vielmehr deren wandelbare, von Ort, Zeit und gesellschaftlichem Umfeld der Aufführung abhängige Erscheinungsformen interessieren. ${ }^{2}$

In diesem Kontext rückt auch das Publikum als ein vom Theaterereignis untrennbarer Bestandteil in den wissenschaftlichen Fokus. Vor allem im Hinblick auf das 19. Jahrhundert, das im mitteleuropäischen Raum durch eine flächendeckende Öffnung von Opernhäusern für ein breites, aus unterschiedlichen gesellschaftlichen Schichten zusammengesetztes Publikum gekennzeichnet war, wird die aktive Rolle des Rezipienten stark gemacht: „Die Teilnehmer an Opernaufführungen des 19. Jahrhunderts waren selber Akteure, die den Charakter eines Abends durch ihre körperliche Präsenz, ihre Bewertung der Musik und ihr Hörverhalten wesentlich prägten",, urteilt Sven Oliver Müller, der im Rahmen seiner

1 Die Schnittstellen zwischen Musik, Oper und Gesellschaft sind beispielsweise zentrales Thema der von Ph. Ther herausgegebenen Schriftenreihe „Die Gesellschaft der Oper. Musikkultur europäischer Metropolen im 19. und 20. Jahrhundert" (München [u.a.] 20062012), in deren zahlreichen Einzelbänden der Versuch unternommen wird, über das $\mathrm{Mu}-$ siktheater einen Zugang zu einer gesamteuropäischen Kulturgeschichte zu schaffen.

2 Vgl. für die theaterwissenschaftliche Auseinandersetzung mit Begriffen und Phänomenen der Performanz stellvertretend R. Schechner, Performance Theory (Routledge Classics), London/New York 1988; Ders., Performance Studies. An Introduction, London/New York 2002; E. Fischer-Lichte, Ästhetik des Performativen (Edition Suhrkamp; 2373), Frankfurt am Main 2004.

3 S. O. Müller, Saalschlachten. Ausschreitungen in Londoner Opernhäusern in der Mitte des 19. Jahrhunderts, in: S. O. Müller / J. Toelle (Hrsg.), Bühnen der Politik. Die Oper in europäischen Gesellschaften im 19. und 20. Jahrhundert (Die Gesellschaft der Oper; 2), Wien/ München 2008, S. 160-176, hier S. 161. Vgl. auch die jüngst im Rahmen des Projekts „Die 
umfassenden Publikumsforschung die These vertritt, dass das Theater zu dieser Zeit sowohl einen Aktions- als auch einen Repräsentationsraum unterschiedlicher sozialer Gruppen darstellte. Indem Oper für ihn „gleichzeitig sozialen Status, kulturelle Verhaltensmuster und politische Ungleichheit [repräsentierte und generierte]", 4 geht er von Wechselwirkungen zwischen Bühne und Auditorium aus, die auch Carlotta Sorba beschreibt, wenn sie in der Oper „a continuous interchange between production and consumption, musical composition and social reality"5 sieht und feststellt: „The relationship between the stage and the real world was a mutual exchange. The action of melodrama sometimes transferred its energy to the public, and sometimes the heroic transfiguration of real life into opera inverted to become a heroic melodramaticization of the real." ${ }^{6}$ Ähnlich konstatiert Bruce McConachie aus theaterwissenschaftlicher Perspektive: „theatre helps people to constitute themselves as social beings", und er definiert eine Aufführung als ,a type of ritual which functions to legitimate an image of a historical social order in the minds of its audience". ${ }^{7}$

Bei aller methodischen Vielfalt, mit der die Wechselwirkungen zwischen Werk und Publikum unter historisch-systematischen, text- und musikwissenschaftlichen, deskriptiven oder theoretischen Aspekten abgehandelt werden können, bleibt doch die grundlegende Beobachtung konstant: Im ,langen' 19. Jahrhundert erlangte die Oper im zentraleuropäischen Raum gesellschaftliche Bedeutung und Popularität in einem Ausmaß, das vorher und nachher unerreicht blieb. In der Zeit zwischen den Werken Wolfgang Amadeus Mozarts und Giacomo Puccinis entfalteten Opern- und Theaterhäuser als zentrale Schauplätze kulturellen und gesellschaftlichen Lebens ihre größte Wirkungsmacht zumindest auf solche Bevölkerungsschichten, denen Kultur aufgrund von Herkunft, Bildung und Besitz zugänglich war.

Davon legen der konstante Anstieg von Theaterbauten und die Vergrößerung der Besucherkreise, die eine neue Öffentlichkeit konstituierten, ebenso Zeugnis ab wie die Erweiterung und Verfestigung eines Opernrepertoires, die Erweiterung von

Gesellschaft macht Musik. Das Opern- und Konzertpublikum in Berlin, London und Wien im 19. Jahrhundert“ der Max-Planck-Forschungsgruppe „Gefühlte Gemeinschaften? Emotionen im Musikleben Europas" erschienene Publikation von S. O. Müller, Das Publikum macht die Musik. Musikleben in Berlin, London und Wien im 19. Jahrhundert, Göttingen 2014.

4 S. O. Müller, Distinktion, Demonstration und Disziplinierung. Veränderungen im Publikumsverhalten in Londoner und Berliner Opernhäusern im 19. Jahrhundert, in: International Review of the Aesthetics and Sociology of Music 37, Heft 2, 2006, S. 167-187, hier S. 168.

5 C. Sorba, To Please the Public. Composers and Audiences in Nineteenth-Century Italy, in: The Journal of Interdisciplinary History 36, Heft 4 (Opera and Society; 2), 2006, S. 595614, hier S. 614.

6 Ebd.

7 B. A. McConachie, Towards a Postpositivist Theatre History, in: Theatre Journal 37, Heft 4, 1985, S. 465-486, hier S. 473. 
personellen und institutionellen Netzwerken als Grundlage rasanter Kulturtransfers, die Etablierung von musikalischen Fachzeitschriften als zentrale Vermittlungsorgane zwischen Werk und Rezipient u.v.m. ${ }^{8}$ In der wissenschaftlichen Betrachtung dieses Phänomens setzte sich aufgrund des zeitlichen Nebeneinanders vom Aufstieg des Bürgertums und vom Aufstieg der Oper in den Mittelpunkt zumindest der zentraleuropäischen ,Hochkultur ${ }^{6}$ die von Theodor W. Adorno ausgehende Ansicht durch, dass die Oper des 19. Jahrhunderts ein genuin bürgerliches Genre sei. ${ }^{9}$ Namentlich in den Ausprägungen der ernsten Gattungen wie der französischen Grand Opéra, dem italienischen Melodramma und dem deutschen Musikdrama, die in der ersten Jahrhunderthälfte von einer Zurückdrängung der antiken und mythologischen Stoffe des barocken Musiktheaters zugunsten romantischer und historischer Sujets der Neuzeit gekennzeichnet waren, glauben Forscher, den Einfluss bürgerlicher Normen und Werte auf die Werkästhetik zu erkennen. So stellt etwa Carl Dahlhaus fest, „daß die Opera seria des 19. Jahrhunderts, auch wenn sie in Hoftheatern aufgeführt wurde, literarisch primär auf das bürgerliche Parkettpublikum als ,Geschmacksträgerschicht ${ }^{6}$ zielte". ${ }^{10}$

Dahlhaus benennt drei Punkte, die wichtig erscheinen, wenn sich im Folgenden das Erkenntnisinteresse auf das Opernpublikum, dessen Zusammensetzung und dessen Verhältnis zu Werk, Bühnengeschehen und den im Werk auftretenden (heroischen) Figuren richten soll: Erstens stellt Dahlhaus einen kausalen Zusammenhang zwischen bürgerlichem Publikum und den gattungstechnischen Entwicklungen der italienischen Opera seria her, die - ebenso wie ihre französischen und deutschen Pendants aus dem Bereich der ernsten, gewissermaßen ,stilhohen' Operngattungen - in der ersten Hälfte des 19. Jahrhunderts in besonderem Maße von dem erwähnten Vordringen romantischer Sujets geprägt war. Weil sich damit einhergehend auch das vormals aus unantastbaren Göttern, siegenden Herrschern, tapferen Kämpfern der mythischen oder vormodernen Zeit zusammengesetzte Heldenpersonal der Opern zu nunmehr gebrochen und psychologisch tiefengeschärft dargestellten Figuren und Gemeinschaften der jüngeren Geschichte wandelte, wäre danach zu fragen, inwiefern dieser Wandel mit der Präsenz bürgerlicher Schichten im Auditorium zusammenhing und ob deren neuartige Hör- und Seherwartungen mit der Präsentation neuartiger Heldenfiguren auf der Bühne korrelierten.

Zweitens lenkt Dahlhaus die Aufmerksamkeit auf das Hoftheater als Ort, an dem sich das bürgerliche Publikum als „Geschmacksträgerschicht“ etablierte. Zwar

8 Vgl. zu sozialgeschichtlichen Aspekten der Oper grundlegend M. Walter, „Die Oper ist ein Irrenhaus“. Sozialgeschichte der Oper im 19. Jahrhundert, Stuttgart/Weimar 1997; A. Gerhard, Die Verstädterung der Oper. Paris und das Musiktheater des 19. Jahrhunderts, Stuttgart 1992.

9 Vgl. Th. W. Adorno, Bürgerliche Oper [1955], in: Th. W. Adorno, Gesammelte Schriften, Bd. 16, Musikalische Schriften 1-3, Frankfurt am Main 1978, S. 24-39.

10 C. Dahlhaus, Die Musik des 19. Jahrhunderts (Neues Handbuch der Musikwissenschaft; 6), Wiesbaden/Laaber 1980, S. 37. 
waren die Hoftheater gerade im italienischen Raum aufgrund der sozialen Strukturen der Kulturmetropolen seit jeher durch hohe Anteile bürgerlicher Schichten gekennzeichnet, dennoch lässt sich damit auf ein Phänomen rekurrieren, das sich zu Beginn des 19. Jahrhunderts flächendeckend in den europäischen Residenzen durchsetzte: So öffneten in zahlreichen Städten die Hoftheater ihre zuvor vielerorts nur einem geschlossenen, aristokratischen Kreis zugänglichen Pforten einem breiten, zahlenden Publikum, wodurch sie sich zu einem Ort wachsender sozialer Durchmischung entwickelten. ${ }^{11}$ Weil Hoftheater infolgedessen von höfischen Subventionierungen und Repräsentationsansprüchen ebenso abhängig waren wie von den Einnahmen aus dem Publikum und somit auch von dessen Geschmacksurteilen, könnten Momente wechselseitiger Beeinflussung und Kontrolle von Hof und Publikum hinsichtlich des Geschehens auf und vor der Bühne aufgedeckt werden. Innerhalb des Auditoriums hebt Dahlhaus, drittens, das Parkett hervor, in dem er das bürgerliche Publikum ansiedelt. Andere Orte des Publikumsraums waren demnach anderen Publikumskreisen zugeordnet, so dass schließlich auch nach dem Zusammenhang zwischen Architektur, Platzierung und Publikum im Raum des Hoftheaters gefragt werden kann.

Im Folgenden sollen diese allgemeinen Ausführungen anhand eines Beispiels konkretisiert werden. Dafür bietet sich das deutsche Hoftheater angesichts seiner Verortung in einer restaurativ geprägten, dezentralen Kleinstaatenkultur im frühen und mittleren 19. Jahrhundert insofern an, als Prozesse der Verbürgerlichung im Vergleich zu großen europäischen Kulturzentren wie etwa Paris oder London nur verzögert und weniger radikal, aber kontinuierlicher abliefen. Im Hinblick auf das allmähliche Vordringen neuer "Geschmacksträgerschichten“ und somit auch neuer opernästhetischer Kriterien in einen vormals höfisch geprägten Raum können daher Merkmale eines gesellschaftlichen Wandlungsprozesses im Raum des Hoftheaters überblicksartig beschrieben werden. Dabei richtet sich der Blick erstens auf das Verhältnis zwischen höfischem Repräsentationswillen und Publikumsanspruch, zweitens auf die konkrete Zusammensetzung, Positionierung sowie Verhaltensmuster des Publikums und drittens schließlich auf die eingangs benannte Wechselbeziehung von Oper und Gesellschaft.

1.

Während sich das deutsche Hoftheater des 18. Jahrhunderts dadurch auszeichnete, dass Opern- und Theatervorstellungen zumeist nur einem exklusiven Publikum zugänglich waren, das sich aus der Hofgesellschaft und eingeladenen örtlichen und durchreisenden Notabeln zusammensetzte, gingen, wie Ute Daniel feststellt, in den 1770er Jahren die ersten deutschen Fürsten dazu über, „ihre Hoftheater durch

11 Vgl. zur Entwicklung der Hoftheater am Beispiel des deutschen Kulturraums grundlegend U. Daniel, Hoftheater. Zur Geschichte des Theaters und der Höfe im 18. und 19. Jahrhundert, Stuttgart 1995. 
festangestellte deutsche Schauspieltruppen bespielen zu lassen und gegen Eintritt einem anonymen Publikum zu öffnen". ${ }^{12}$ Zunächst beschränkt auf die großen deutschen Königshäuser sowie den Wiener Kaiserhof und vereinzelt auch kleinere Residenzen wie zum Beispiel Weimar oder Esterháza, sollten zu Beginn des 19. Jahrhunderts weitere deutsche Höfe ihre Theater öffentlich zugänglich machen und so direkte Berührungspunkte zwischen Fürst, Hof und Residenzbevölkerung schaffen. Diese Berührungspunkte bildeten die Grundlage für eine Wechselbeziehung zwischen Obrigkeit und Publikum, die für das deutsche Hoftheater des Vormärz konstitutiv war. Das Publikum war zwar am Hof der Sozialdisziplinierung ausgesetzt und hatte sich dem höfischen Reglement zu unterwerfen. Aber zugleich hatte der Opernbesucher auch die Möglichkeit zu Bildung, Unterhaltung sowie zur Demonstration seiner Loyalität dem Regenten gegenüber. Das deutsche Hoftheater wandelte sich auf diese Weise, wie Andreas Münzmay am Beispiel des Stuttgarter Theaters darlegt, zunehmend

„von einem rein höfischen - zur Unterhaltung des Adels [...] und zur herrscherlichen Repräsentation dienenden - Ort barocker Manier, an dem der Öffentlichkeit allenfalls eine Rolle als Zuschauer (sowohl des Theaterstücks als auch vor allem des Hofes selbst) zukam, in eine primär öffentliche Einrichtung, die unabhängig von höfischer Präsenz sinnhaft war und funktionierte, aber gleichzeitig vom König weiterhin privilegiert benutzt werden konnte." ${ }^{13}$

Um die Präsenz eines öffentlichen Publikums in einem vormals exklusiv höfischen Raum zu legitimieren, erhielt das deutsche Hoftheater nicht zuletzt vor dem Hintergrund aufklärerischer Ideen vielerorts den ästhetischen Rang einer Erziehungsanstalt. So definierte der Wiener Hof 1817 die Stellung der kaiserlichen Theater als eine Einrichtung, ,an dessen Vergnügen dem Publikum unter bestimmten Bedingungen und Vorschriften teilzunehmen gestattet ist, in welcher Hinsicht die Hoftheater zugleich in die Kategorie einer öffentlichen auf die Sittlichkeit und Bildung des Publikums berechneten Anstalt eintreten ". ${ }^{14}$ Hinter diesem Bildungsaspekt verbargen sich, Daniel zufolge, jedoch auch kulturpolitische Motive: Der infolge des Wiener Kongresses 1814/15 einsetzende ,sparsamere Zuschnitt der Hofhaltungen und die geringere Bedeutung der höfischen Luxusausgaben als Mittel der sozialen Abgrenzung "15 bewirkte auch, dass am Hof ein gewissermaßen ,verbürgerlichter Habitus zur Schau gestellt wurde. So gingen Regenten nunmehr verstärkt „auf diejenigen Aspekte ,aufklärerischen' Gedankenguts bildungsbürgerlicher Provenienz ein, die geeignet waren, diese neue Mode zu mehr als einer Notlösung zu

12 Ebd., S. 66.

13 A. Münzmay, Musikdramaturgie und Kulturtransfer. Eine gattungsübergreifende Studie zum Musiktheater Eugène Scribes in Paris und Stuttgart (Forum Musikwissenschaft; 5), Schliengen 2010, S. 234.

14 Zitiert nach H. Zielske, Zwischen monarchischer Idee und Urbanität. Hoftheater und Stadttheater im Vormärz, in: M. Porrmann / F. Vaßen (Hrsg.), Theaterverhältnisse im Vormärz (Jahrbuch / Forum Vormärz-Forschung; 7.2001), Bielefeld 2002, S. 43-69, hier S. 50.

15 Daniel, Hoftheater (Anm. 11), S. 117. 
machen" ${ }^{16}$ Das Hoftheater eignete sich optimal als Ort dieser Zurschaustellung, vereinte es doch den Regenten, der das Theater als Hort für Kunst, Bildung und Unterhaltung ermöglichte und subventionierte, das Publikum, das dies durch finanzielle Gegenleistung aufnahm, und den Künstler, der als direkter Vermittler zwischen Kunst und Publikum auftrat, unter einem Dach. Dies verdeutlicht auch der Artikel „Hof-Theater“ des „Allgemeinen Theater-Lexikons“ von 1841:

„Als das deutsche Theater anfing, zu einer bestimmten Selbstständigkeit zu erwachen [...], da nahmen kunstsinnige Fürsten sich seiner an, schützten und bewahrten es, sicherten die Zukunft der Künstler und gaben den Instituten einen festen Halt im Anlehnen an die geordneten Verhältnisse der Hofhaltungen. [...]

Der Regent hat durch ein H.[of]=T.[heater] Gelegenheit sich täglich in der Mitte seiner Unterthanen zu zeigen, ohne der zu großen Annäherung des Publikums ausgesetzt zu sein, bei Besuchen fremder fürstl. Personen erspart ein glänzendes Theater dem Hofe die ungleich kostbarern Hoffestlichkeiten als Jagden, Bälle, Maskeraden u.s.w.; das Publikum hat Gelegenheit die hohen Gäste zu sehen [...]. Für die Kunst liegt der Vortheil, den $\mathrm{H} .=\mathrm{T}$. gewähren, in dem dauernden Zusammensein und Zusammenwirken der darstellenden Künstler, in den geordneten Verhältnissen überhaupt, in der Rücksicht, daß auf solchen Bühnen sich das Repertoir fest gestalten und dem Anbringen der seichten Tageserzeugnisse sich wehren läßt. [...] Für das Publikum in dem reichen und doch in seinen Grundzügen festern Repertoire, in der Gewißheit eine gesittete, anständige Versammlung zu finden, auf welche die Gegenwart des Hofes einen entschiedenen wohlthätigen Einfluß ausübt, endlich aber in der besseren Ausstattung der Vorstellungen. ${ }^{.17}$

Hier wird das Verhältnis zwischen Monarch und Publikum an einem Hoftheater als nutzbringend für beide Seiten beschrieben. Dem Fürsten war die Möglichkeit einer mittelbaren, verwaltungstechnisch geregelten und finanziell überschaubaren Selbstrepräsentation seinen Gästen und dem Publikum gegenüber gegeben, während dieses neben der allgemeinen Zugänglichkeit der Theater von den Vorteilen einer stehenden Bühne mit festem Repertoire und fest angestelltem künstlerischen Personal, also einer Art von Qualitätssicherung der künstlerischen Erzeugnisse, profitieren konnte.

Durch seine Präsenz im Hoftheater formte das Publikum also eine neue Öffentlichkeit und Trägerschicht eines Geschmackes, der mit den fürstlichen Ansprüchen in Übereinstimmung zu bringen war. Dabei lässt sich der im Artikel erwähnte Repräsentationsanspruch eines Regenten, der sich im Theater „in der Mitte seiner Unterthanen" zeigen konnte, besonders deutlich an Festvorstellungen anlässlich fürstlicher Jubiläen und Feiertage beschreiben, auf deren Mitgestaltung ein Fürst durch finanzielle Zuschüsse großen Einfluss nehmen konnte. Dass zum Beispiel Gioacchino Rossinis Oper „Guillaume Tell“ im Oktober 1830 an der Berliner Hofoper anlässlich der Vermählung des Prinzen Albrecht von Preußen erstmals aufgeführt wurde, kann einerseits als direktes Zugeständnis des Hofes an einen Publi-

16 Ebd., S. 117-118.

17 L. Schneider, Hof-Theater, in: R. Blum [et al.] (Hrsg.), Allgemeines Theater=Lexikon [...], 7 Bde., Bd. 4, Altenburg/Leipzig 1841, S. 241-243, hier S. 241, S. 242-243. 
kumsgeschmack gedeutet werden, der sich in den 1820er Jahren in Berlin zentral an den Opern Rossinis orientierte. Weil die Aufführung andererseits zu einem großen Teil aus der Privatkasse König Friedrich Wilhelms III. von Preußen finanziert wurde, erschien die Oper Rossinis in Berlin jedoch im Gewand einer stark bearbeiteten Version unter dem Titel „Andreas Hofer“, die die revolutionär-liberale Aussage des Werkes in eine konservativ-monarchische umwandelte. ${ }^{18}$ Indem also modifizierend in die Werkgestalt eingegriffen wurde, konnte der Spagat zwischen Publikumsanspruch und fürstlichem Repräsentationswillen bewerkstelligt werden.

An kleineren Hoftheatern, die in weit höherem Maße auf fürstliche Zuschüsse angewiesen waren als die Publikumsmagneten der deutschen Großstädte, schlugen sich Vorlieben der Regenten bei der Gestaltung der Vorstellungen und des Spielplans noch deutlicher nieder. In einer mittelgroßen Residenzstadt wie beispielsweise Weimar bevorzugte Großherzog Carl Friedrich in den 1820er und 1830er Jahren die Aufführung von Balletten, während seine Gattin Maria Pawlowna ein großes Interesse an klassischen Opern des ausgehenden 18. Jahrhunderts hegte. Auf den Weimarer Spielplänen finden sich daher zu dieser Zeit vor allem an den Tagen großherzoglicher Festvorstellungen zu Ehren Carl Friedrichs Ballette sowie zu Ehren Maria Pawlownas Werke Mozarts und Glucks. ${ }^{19}$ In Stuttgart hingegen, wo die königliche Familie um Wilhelm I. von Württemberg herum weniger das historische als vielmehr das aktuelle Opernrepertoire bevorzugte, wurden zwischen den 1820er und frühen 1860er Jahren vor allem die königlichen Geburtstage zum Anlass genommen, große und aktuelle Opern aufzuführen. ${ }^{20}$

Opernvorstellungen, die in den Rahmen höfischer Feierlichkeiten eingebunden waren, stellten demnach in Bezug auf das Wechselverhältnis zwischen Hof und Publikum besonders signifikante Ereignisse dar - sie bildeten einen Kristallisationspunkt, an dem die Interessen des Hofes und des Publikums aufeinandertrafen. Hier konnte der Regent einen großen, durch finanzielle Unterstützung erwirkten Einfluss auf die Gestaltung des Spielplans ausüben und durch die Auswahl von Stücken, die ein großes Publikum anzogen, signalisieren, wie er sich innerhalb des verbreiteten Geschmacks positionierte. Demgemäß stellt Münzmay in Bezug auf Stuttgart fest, dass Theatervorstellungen im Umfeld höfischer Feste nicht nur die einzigen waren, „bei denen überhaupt ein direkter höfischer Einfluss auf die Programmgestaltung des Theaters abzulesen ist, sondern sie markieren auch einen besonders engen Berührungspunkt von höfischer Repräsentation und städtischer Öffentlichkeit“. ${ }^{21}$ Dass etwa in Stuttgart die Grand Opéra „La Muette de Portici“ von

18 Vgl. zu der Berliner Umarbeitung des „Guillaume Tell“ Ch. Henzel, Tell in Tirol. Zu einer antirevolutionären Rossini-Bearbeitung, in: T. Ott / H. von Loesch (Hrsg.), Musik befragt, Musik vermittelt. Peter Rummenhöller zum 60. Geburtstag, Augsburg 1996, S. 405-420.

Vgl. dazu näher C. Bahr, Zur Entwicklung der Oper am Weimarer Hoftheater zwischen 1817 und 1840, in: O. Breidbach (Hrsg.), Vom Ende des Ereignisses (Laboratorium Aufklärung; 7), München/Paderborn 2011, S. 123-136.

20 Vgl. Münzmay, Musikdramaturgie und Kulturtransfer (Anm. 13), S. 300-301.

21 Ebd., S. 300. 
Daniel-François-Esprit Auber zum Geburtstag König Wilhelms I. am 4. September 1830 erstmals aufgeführt wurde, obwohl wenige Tage zuvor eine Vorstellung dieser Oper in Brüssel den Anlass bildete für politische Unruhen und die Stürmung des Brüsseler Justizpalastes, ${ }^{22}$ konnte mithin als liberaler Akt und Vertrauensbekundung des Königs seinem Volk gegenüber verstanden werden. ${ }^{23}$ Ähnliche Intentionen mochte in Weimar Großherzogin Maria Pawlowna verfolgt haben, als sie anlässlich ihres Geburtstags am 16. Februar 1831 im Umfeld der Pariser Julirevolution Rossinis Freiheitsoper „Guillaume Tell“ erstmals aufführen ließ. Auch Giacomo Meyerbeers 1836 in Paris uraufgeführte Grand Opéra „Les Huguenots“, die aufgrund der brutalen Darstellung des Glaubenskampfes zwischen Hugenotten und Katholiken im Umfeld der sogenannten Bartholomäusnacht (1572) in vielen deutschen Residenzen nicht aufgeführt werden durfte, fungierte vereinzelt als Festvorstellung: Dass das Werk zum Beispiel in Stuttgart 1842 am Geburtstag des Königs erstmals aufgeführt wurde, konnte „sicherlich auch als Zeichen gegen religiöse Eiferer jeder Konfession in Württemberg verstanden werden". ${ }^{24}$ In Preußen wiederum ernannte der seit 1840 amtierende König Friedrich Wilhelm IV. Meyerbeer 1842 zum preußischen Generalmusikdirektor der Hofoper und ließ zu Meyerbeers Einstand „Les Huguenots“ am 20. Mai 1842 erstmals in Berlin aufführen. Dadurch grenzte er sich von der konservativen Kulturpolitik seines Vaters Friedrich Wilhelms III. ab, unter dessen Regentschaft die Aufführung der Oper bis zuletzt verboten war.

Die genannten Beispiele zeigen, dass der Einfluss höfischen Repräsentationswillens durch die Entstehung einer Öffentlichkeit im deutschen Hoftheater nicht verdrängt wurde, sondern mit dieser in eine Wechselbeziehung trat: In Form von repräsentativen Aufführungen konnte ein deutscher Regent einerseits seine Nähe zum Publikumsgeschmack demonstrieren und andererseits auf die musikalische und szenische Gestaltung der Aufführung Einfluss nehmen. Dem Besucher dieser Vorstellungen war hingegen die Möglichkeit gegeben, eine populäre Oper in einer Erstaufführung oder Neuinszenierung zu erleben. Der besondere Reiz kann für den Besucher darin gelegen haben, Teil eines gesellschaftlichen und medialen Großereignisses zu werden, lösten die mit überdurchschnittlich hohen finanziellen und künstlerischen Mitteln ausgestatteten Aufführungen doch häufig ein großes Presseecho in den Tages- und Musikzeitungen aus. Wenn dabei jedoch angenommen wird, dass das Theater für das Publikum, wie im „Allgemeinen TheaterLexikon“ kritisch bemerkt wird, „in allen seinen Productionen eine Vergnügungs-

22 Interessanterweise handelte es sich bei dieser legendären Brüsseler Aufführung von „La Muette de Portici“ am 25. August 1830 ebenfalls um eine Festvorstellung anlässlich des Geburtstags von König Wilhelm I. der Niederlande; vgl. zum Zusammenhang der Brüsseler Aufstände mit der Opernaufführung etwa Walter, „Die Oper ist ein Irrenhaus“ (Anm. 8), S. 264-266; Gerhard, Die Verstädterung der Oper (Anm. 8), S. 115-121 (Abschnitt „Oper und Revolution“).

23 Vgl. Münzmay, Musikdramaturgie und Kulturtransfer (Anm. 13), S. 302-303.

24 Ebd., S. 301. 
anstalt ${ }^{\text {“25 }}$ darstellte, so muss geklärt werden, wie sich dieses Publikum überhaupt zusammensetzte und welche Handlungsmotive einen Opernbesuch bestimmten.

2.

Vor dem Hintergrund, dass sich die deutschen Hoftheater im 19. Jahrhundert mithilfe staatlicher und fürstlicher Zuschüsse zu einem Großteil selbst verwalteten, gewann das Publikum vor allem eine wirtschaftliche Bedeutung: Seine Kaufkraft diente als wesentliches Mittel zur Finanzierung des Theaters. So war, nach Michael Walter, die „Öffnung der Hoftheater in Deutschland [...] kein Akt der Demokratisierung, sondern einer der finanziellen Notwendigkeit“. ${ }^{26}$ Fragt man also nach der sozialen Reichweite des deutschen Hoftheaters als Ort des Aufeinandertreffens von Obrigkeit und Publikum, muss man sich vergegenwärtigen, dass der häufig undifferenziert verwendete Begriff ,das Publikum' keinesfalls als repräsentatives Abbild der deutschen Gesamtbevölkerung dienen kann, solange das Attribut ,zahlungsfähig' nicht mitgedacht wird. Denn das „gesamte ,Volk ${ }^{6}$ als Theaterpublikum - wenn man darunter auch die Arbeiterschaft [...] versteht war eine fiktive Größe, da aufgrund der Eintrittspreise sich das, Volk' im Theater im Wesentlichen aus großbürgerlichen und geringen kleinbürgerlichen Anteilen zusammensetzte“". ${ }^{27} \mathrm{Da}$ eine Eintrittskarte noch am Ende des 19. Jahrhunderts an größeren deutschen Bühnen rund die Hälfte des durchschnittlichen Wochenlohns eines Arbeiters gekostet hat, waren regelmäßige Opernbesuche für diesen kaum finanzierbar. ${ }^{28}$ Das durchschnittliche deutsche Theaterpublikum muss sich also vor allem aus Angehörigen aristokratischer sowie solcher bürgerlicher Gesellschaftsschichten zusammengesetzt haben, die sich einen Opernbesuch sowohl in finanzieller als auch in zeitlicher Hinsicht leisten konnten.

25 L. Schneider, Publicum, in: R. Blum [et al.] (Hrsg.), Allgemeines Theater=Lexikon [...], 7 Bde., Bd. 6, Altenburg/Leipzig 1842, S. 138-140, hier S. 139.

26 Walter, „Die Oper ist ein Irrenhaus“ (Anm. 8), S. 320.

27 Ebd., S. 322.

$28 \mathrm{Vgl}$. ebd. Eine Auflistung von Eintrittspreisen an ausgewählten europäischen Opernhäusern vor 1848 findet sich ebd., S. 95-96. Bezeichnenderweise bildete sich im 19. Jahrhundert der Begriff des Sonntagspublikums heraus, mit dem jener Teil des Publikums gemeint war, der sich einen Opernbesuch allenfalls an einem werkfreien Tag und dann auch lediglich in einem kostengünstigen Preisbereich (meist in der Galerie eines Theaters) leisten konnte. Demgemäß wird im Allgemeinen Theater-Lexikon auch dezidiert zwischen dem Sonntags- und dem wohlhabenderen Publikum hinsichtlich des finanziellen Vorteils für ein Theater unterschieden: „Obgleich der Vorstand eines Theaters auch auf die Theilnahme der niedern Stände angewiesen ist, welche das sogenannte Sonntags=P[ublikum $]$. bilden, so kann er doch für die Dauer nur auf die Unterstützung der Wohlhabendern unter den Einwohnern einer Stadt rechnen“, Schneider, Publicum (Anm. 25), S. 139 (Hervorhebung im Original). An anderer Stelle wird darauf hingewiesen, dass mit dem „regelmässig guten Besuch [des Sonntagspublikums] nicht zu rechnen“ ist und es allenfalls „an Sonn- und Feiertagen[,] besonders wenn Spektakelstücke gegeben werden“, das Theater besucht, L. Schneider, Gallerie, in: R. Blum [et al.] (Hrsg.), Allgemeines Theater=Lexikon [...], 7 Bde., Bd. 3, Altenburg/Leipzig 1840, S. 334-336, hier S. 335. 
Der Weg zwischen dem Entschluss eines Regenten, sein Hoftheater einem nichtaristokratischen, zahlenden Publikum zu öffnen, und dessen Realisierung verlief indes keineswegs reibungslos. Aus Berlin etwa wurde im Jahr 1799 in einer Monatszeitschrift berichtet, dass „die Absicht des Königs, dem ganzen Publikum ein Vergnügen zu verschaffen, [...] großtheils vereitelt" ${ }^{\text {"29 }}$ wurde. Denn bis auf einen kleinen Teil frei verkäuflicher Karten war der Großteil der Plätze in der Berliner Hofoper lediglich einem privilegierten Kreis von Offizieren, hohen Beamten und Hofangehörigen vorbehalten:

„Die Oper kann itzt nur von einem Theil des Publikums besucht werden, nur von demjenigen Theile der seine angewiesenen Plätze hat: nehmlich von den Offizieren, den obern Zivilbedienten, und von solchen Personen die zum Hofe gehören. Für Fremde, denen ihr Stand nicht erlaubt am Hofe zu erscheinen, für die Mitglieder derjenigen Kollegien welche erst in spätern Zeiten errichtet worden sind, für die subalternen Zivilbedienten, und für die ganze achtungswürdige Klasse der Fabrikanten, Kaufleute, Künstler, und der gebildetern Handwerker, ist kein Raum vorhanden. “30

Zur Minderung des hohen Anteils an Offizieren und Beamten, die in der Regel weniger an der Opernvorstellung, sondern vielmehr an der Repräsentation ihrer selbst interessiert waren, ${ }^{31}$ forderte der Autor die allgemeine Erhebung von Eintrittsgeldern. Da die Hofoper auf diese Weise für ein interessiertes Publikum zugänglich gemacht würde, könne „die neue Einrichtung zur Verfeinerung der Sitten etwas beitragen". ${ }^{32}$ Der Autor vertrat damit die in der Zeit um 1800 durchaus progressive Vorstellung, dass nicht die Zugehörigkeit zum höfischen Zeremoniell das entscheidende Kriterium eines gesitteten Opernbesuchs darstelle, sondern die Zahlungsfähigkeit des Besuchers, durch die eben auch dem wohlhabenden Bürger der Zugang zur Hofoper ermöglicht werden sollte. Dass die Berliner Theaterleitung zu dieser Zeit jedoch nur wenige Eintrittskarten in den freien Verkauf gab, wurde in dem Artikel unter anderem mit der Gefahr und der Angst des wohlhabenden Publikums vor dem Eindringen niederer Bevölkerungsschichten begründet. Denn der Direktion war es

„unmöglich, zu verhüten daß mit den Billetten nicht vielfältiger Mißbrauch getrieben werde. Eine Menge derselben werden von den angesehensten Personen, oder doch auf den Namen derselben, verlangt; gerathen aber in die Hände von Leuten aus der niedrigsten Klasse. Natürlich hält dies Viele ab, sich um Billette, besonders für ihre Frauen und Töchter, zu bemühen; man fürchtet die Nachbarschaft." ${ }^{\text {"33 }}$

29 Th., Ein Vorschlag, die Berlinische Oper und Redoute betreffend, in: Neue Berlinische Monatsschrift 1, April 1799, S. 241-260, hier S. 248.

30 Ebd. Der Artikel wird eingehend besprochen bei M. Walter, Distinktionsmerkmale des Opernpublikums am Ende des 18. Jahrhunderts, in: T. Betzwieser [et al.] (Hrsg.), Bühnenklänge. Festschrift für Sieghart Döhring zum 65. Geburtstag, München 2005, S. 489-500.

31 Vgl. zur Zusammensetzung und zum Verhalten des Berliner Opernpublikums Ch. Henzel, Die italienische Hofoper in Berlin um 1800. Vincenzo Righini als preußischer Hofkapellmeister, Stuttgart/Weimar 1994, besonders S. 29-37 (Kapitel „Opernhaus und Publikum“). Th., Ein Vorschlag, die Berlinische Oper und Redoute betreffend (Anm. 29), S. 259.

33 Ebd., S. 249. 
Erst zögerlich und unter den genannten Vorbehalten jener, die sich plötzlich mit der „Nachbarschaft“ von Menschen niederen Ranges konfrontiert sahen, öffnete die Berliner Hofoper in den 1810er und 1820er Jahren nicht zuletzt aus Gründen finanzieller Engpässe mehr und mehr Plätze einem nicht-exklusiven Publikum. Das Resultat dieser Entwicklung, die sich so oder ähnlich auch in anderen deutschen Residenzstädten vollzog, war eine wachsende soziale Durchmischung und Heterogenität des Publikums, die im Vergleich zu großen Kulturmetropolen wie etwa Paris weitaus größer ausfiel. Dort nämlich bewirkte das Vorhandensein verschiedener großer Operneinrichtungen eine Aufteilung der Bevölkerungs- und damit auch „Geschmacksträgerschichten“ auf die einzelnen Häuser: Während sich in der Opéra auch das Bürgertum unter das sonst vornehmlich aristokratische Publikum mischte, stellte das Théâtre-Italien vor allem einen exklusiven Treffpunkt aristokratischer Kreise dar. ${ }^{34}$

Dieses Nebeneinander ebenbürtiger Bühnen fand sich nur bedingt in deutschen Residenzstädten, verfügten diese doch neben der Hofbühne bestenfalls über kleinere, privat oder städtisch finanzierte Theaterhäuser. Der Umstand, dass zumeist ausschließlich die Hofbühnen eine staatliche Privilegierung und Finanzierung genossen, führte zu einer Monopolisierung des Vergnügungsangebotes im Hoftheater. Die Bevölkerung war so, nach Daniel, „zur Befriedigung ihrer Schaulust mehr oder weniger auf das Hoftheater angewiesen " 35 Weil demnach die Heterogenität des Publikums umso größer war, je weniger alternative Vergnügungsangebote ihm zur Verfügung standen, stieg folglich „die soziale Durchmischung des Publikums im umgekehrten Verhältnis zur Größe der Residenzstadt an" ${ }^{36}$ Je kleiner die Stadt war, umso geringer fielen die alternativen Unterhaltungsangebote aus und umso größer war die Wahrscheinlichkeit, dass Angehörige verschiedener sozialer Schichten in einem Hoftheater zusammentrafen.

Die Vereinigung von Menschen unterschiedlicher sozialer Herkunft an einem öffentlichen Ort steigerte in den Augen einiger Beobachter in der Zeit des Vormärz den politischen und ideellen Stellenwert des Theaters im Prozess der Demokratisierung der Gesellschaft. ${ }^{37}$ Der großherzoglich Badische Oberbaudirektor Friedrich Weinbrenner etwa, der bereits 1809 fundamentale Überlegungen über das Theater als Erziehungsinstitution anstellte, war von der Idee durchdrungen, dass sich einzelne Gruppen im Theater auf harmonische Weise gegenseitig beeinflussten:

34 Zur Publikumsstruktur der Pariser Opernhäuser vgl. Gerhard, Die Verstädterung der Oper (Anm. 8), S. 29-36 (Abschnitt „Opern für ein neues Publikum“); S. Huebner, Opera Audiences in Paris 1830-1870, in: Music \& Letters 70, Heft 2, 1989, S. 206-225.

35 Daniel, Hoftheater (Anm. 11), S. 130.

36 Ebd., S. 131.

37 Vgl. dazu ausführlich J. Meyer, Theaterbautheorien zwischen Kunst und Wissenschaft. Die Diskussion über Theaterbau im deutschsprachigen Raum in der ersten Hälfte des 19. Jahrhunderts (Studien zur Geschichte der Architekturtheorie), Zürich/Berlin 1998, besonders S. 159-201 (Kapitel „Die soziale Funktion des Theaters: Das Publikum und sein Einfluss auf die Konzeption der Auditorien"). 
„Unter die beliebtesten öffentlichen Gebäude der neuern Zeit gehören unstreitig die Theater. Für sie interessirt sich bei weitem der grössere Theil des Publikums, ohne Unterschied des Standes, der Religion, der Bildung. Sie sind der allgemeinste Vereinigungsort, wo Menschen sich nicht nur sehen, sondern auch wechselseitig, nach den Graden ihrer Bildung sich Ideen und Gefühle ihres Wohlgefallens oder Missfallens an den gegebenen Vorstellungen mittheilen. “38

Auch der Schauspieler und Schriftsteller August Lewald, der als Korrespondenzpartner (und Publizist) der politischen und musikkulturellen Beobachtungen Heinrich Heines bekannt geworden ist und 1835 die liberale Zeitschrift „Europa“ gründete, erhob in seinem „Theater-Roman“ 1841 das Theater zu einem Ort, der „in unsern gesellschaftlichen Beziehungen im engern Sinne das einzige, öffentliche Element" und „für einen großen Theil der Menschen wirklich die ganze ge-

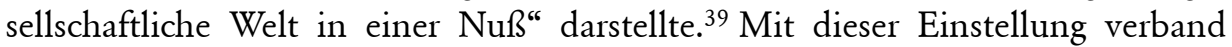
sich die Ansicht, dass dem von einem „großen Theil der Menschen“ gemeinsam rezipierten Kunstprodukt - dem Schauspiel und der Oper - ein Identität, wenn nicht gar Gemeinsinn stiftendes Moment innewohne. ${ }^{40}$ Vor dem Hintergrund sozialgeschichtlicher Entwicklungen wurde der Kunst eine soziale Dimension und dem Theater eine Bedeutung als sozialer Lebensraum, als auf einen Ort eine „Nuß“ - konzentrierter Spiegel der Gesellschaft beigemessen.

Dabei dienten einige der zahlreichen Genres und Gattungen, die sich zu dieser Zeit im Bereich des Schauspiels und der Oper neu herausbildeten, als Modelle und potenzielle Ausdrucksformen einer Kunst, die kulturelle Grenzen dauerhaft aufzulösen vermochte. Als etwa die Welle der Begeisterung, die Aubers „La Muette de Portici“" in Paris auslöste, in den deutschen Raum übertrat, prognostizierte man 1830 in der Musikzeitschrift „Cäcilia“, die Oper werde sich „vielleicht ein Jahrhundert mindestens auf der Bühne halten; ihr Genre gehört allen Ländern, allen Zeiten, den Gebildetsten wie den untersten Volksklassen an". ${ }^{41}$ Offenbar wurde mit dieser Oper, in der die revolutionäre Erhebung von neapolitanischen Fischern gegen die spanische Fremdherrschaft im mittleren 17. Jahrhundert thematisiert wird, ein Wandel im sozialen Stellenwert von Kunst assoziiert: Einerseits entwickelte sich die Idee der Langlebigkeit von musikalischen Werken

38 F. Weinbrenner, Über Theater in architektonischer Hinsicht mit Beziehung auf Plan und Ausführung des neuen Hoftheaters zu Carlsruhe, Tübingen 1809, S. 1.

39 A. Lewald, Theater-Roman, Stuttgart 1841, S. III-IV. Auch zitiert in Münzmay, Musikdramaturgie und Kulturtransfer (Anm. 13), S. 238.

40 Vgl. Meyers Ausführungen über den Zusammenhang von Publikum, Theaterbau und der Entwicklung der Idee einer ,absoluten Kunst' in Meyer, Theaterbautheorien (Anm. 37), besonders S. 194-201 (Abschnitt „Von der ,ästhetischen Kunst' zur ,Lebenskunst': das Theater als Forum der absoluten Kunst"). Mit der sozialen Funktion von öffentlichen Theatern in der Zeit des Vormärz beschäftigt sich auch eingehend I. Matthes, „Der allgemeinen Vereinigung gewidmet“. Öffentlicher Theaterbau in Deutschland zwischen Aufklärung und Vormärz (Theatron; 16), Tübingen 1995.

41 Lindner, Ueber die Verpflanzung neuester französischer Opern auf die Bühnen und den Musikalienhandel Teutschlands, in: Cäcilia, eine Zeitschrift für die musikalische Welt 12 [Mainz], Heft 45, 1830, S. 35-54, hier S. 40. 
(in Zeiten eines erst schwach ausgeprägten Repertoiresystems war die Vorstellung, eine Oper würde sich „ein Jahrhundert mindestens auf der Bühne halten“, geradezu utopisch), und andererseits verband sich mit der Grand Opéra, als deren erste Vertreterin „La Muette de Portici“ gilt, die Vorstellung eines „Genres“, das nicht elitär war, sondern die Grenzen zwischen Klassen und Ländern aufzulösen vermochte.

Mit der Realität des Theaters als Begegnungsort verschiedener Bevölkerungsschichten hatten diese idealisierenden Anschauungen jedoch eine nur geringe Schnittmenge. Das Theater stellte weniger einen Ort der Vereinigung und Verständigung zwischen verschiedenen Gruppierungen dar, als vielmehr einen höchst heterogenen sozialen Raum, in dem unterschiedliche Verhaltensweisen kultiviert wurden. Wo Gegensätze aufeinandertrafen, Adel auf Bürgertum, Männer auf Frauen, Protestanten auf Katholiken, Musikkenner auf Musikliebhaber, war man nicht nur „penibel darauf bedacht[,] Klasse, Geschmack und Habitus herauszustellen "42 und sich durch unterschiedliches Verhalten voneinander abzugrenzen, sondern es wurden durch den regelmäßigen und geregelten Theaterbesuch zugleich auch neue kulturelle Verhaltensmuster generiert.

Die Beobachtungen, die der Berliner Hofschauspieler Louis Schneider diesbezüglich $1842 \mathrm{im}$ „Allgemeinen Theater-Lexikon“ über das Publikum anstellte, machen deutlich, dass sich in den unterschiedlichen Bereichen des Zuschauerraums unterschiedliche Praktiken herausbildeten, mit denen sich die Gruppen voneinander abgrenzten:

„Welch ein Abstand von dem Studenten, der nach sorgfältiger Vorbereitung durch wiederholtes Lesen einer klassischen Dichtung mit dem Buche in der Hand der Darstellung im Parterre folgt, bis zu dem Vornehmen, der nach einem glänzenden Diner gähnend in den Logen des 1. Ranges verdaut; von dem Handwerker, der Sonntags seine Familie mit den Ersparnissen der Woche auf die Gallerie führt, bis zu dem Musikkenner, der, den Klavierauszug in der Hand, die Leistung des Orchesters und der Sänger beurtheilt. Die höchste geistige Bildung neben der rohesten Vergnügungssucht, der Glanz und die Behaglichkeit der bevorrechteten Stände neben dem Mangel und der niedrigen Neigung! $" 43$

Die Zusammenführung von Gesellschaftsschichten in einem Raum war eine wesentliche Folgeerscheinung der Öffnung von Hoftheatern, denn diese waren auf ein differenziertes, aus verschiedenen Bevölkerungsschichten zusammengesetztes Publikum angewiesen, wollten sie eine möglichst hohe Auslastung und damit wirtschaftliche Selbstständigkeit erreichen. Dergestalt unter einem Dach vereint, also räumlich miteinander vermischt, wurden nunmehr innerhalb des Auditoriums Abgrenzungsmechanismen in Bezug auf Rezeptionsverhalten und Platzwahl in Gang gesetzt. Indem der Adel, die Hofangehörigen und Verwaltungsspitzen im ersten Rang, das gutsituierte Bürgertum im Parkett und der Rest, bestehend aus

42 Müller, Distinktion, Demonstration und Disziplinierung (Anm. 4), S. 168.

43 Schneider, Publicum (Anm. 25), S. 138-139. 
Studenten, Kaufleuten, Offizieren, an werkfreien Tagen auch Angehörigen niedrigerer Bevölkerungsschichten, in den oberen Rängen, der Galerie und im Stehparkett anzutreffen waren, standen die Architektur der Opernhäuser und das Publikumsverhalten in einer engen Wechselbeziehung. ${ }^{44}$

Die unterschiedlichen Verhaltensweisen spiegelten sich in der räumlichen Unterteilung des Auditoriums wider: einerseits in der Staffelung von Eintrittspreisen, von den teuersten Plätzen in den vorderen Parkettreihen sowie den ersten Logen, die mit komfortablen Sitzen ausgestattet waren und einen guten Blick auf die Bühne boten, bis hin zu den um ein Vielfaches billigeren Plätzen in den Galerien, die zumeist nur mit einfachen Holzbänken oder Stehplätzen ausgestattet waren, ${ }^{45}$ andererseits in den gesonderten Treppenaufgängen und Foyers. Die räumliche Trennung der repräsentativen, prunkvollen Aufgänge ins Hauptgeschoss oder gar in die königliche Loge von den oft schmucklosen Nebenaufgängen zu den oberen Rängen und der Galerie war darauf angelegt, ein Aufeinandertreffen der verschiedenen Gruppen beim Eintritt in das Theatergebäude sowie in den Pausen zu vermeiden. ${ }^{46}$

Auf diese Trennung wurde auch bei Theaterneubauten in der ersten Hälfte des 19. Jahrhunderts teils penibel Wert gelegt: Als beispielsweise in Stuttgart in den 1830er Jahren ein Neubau des Hoftheaters geplant wurde, bemängelten die höfischen Gutachter in Bezug auf die geplanten Treppenaufgänge zu den Rängen und zugleich zur Galerie, „daß 3/4 Theile der Zuschauer nämlich die des zweiten und dritten Ranges gemischt mit denen der obersten 4ten Gallerie [...] herunter und hinaufgehen müssen ". ${ }^{47}$ Eine Trennung sollte hier nicht nur zwischen aristokratischen und bürgerlichen Schichten vollzogen werden, sondern gar innerhalb des

44 Vgl. zur Positionierung der verschiedenen Publikumsschichten Walter, Distinktionsmerkmale des Opernpublikums (Anm. 30), besonders S. 490-492.

45 Über die allgemeine Staffelung von Eintrittspreisen berichtet ausführlich D. F. von Linstow, Beiträge zur zweckmäßigen Anordnung des Zuschauerraumes in Schauspielhäusern, in: Allgemeine Bauzeitung 9 [Wien], 1844, S. 207-221. Der Artikel bietet einen überaus wichtigen Einblick in die Bau- und Funktionsweise von öffentlichen Hoftheatern in der ersten Hälfte des 19. Jahrhunderts. Er veranschaulicht ferner, wie wichtig der finanzielle Aspekt bei der Öffnung der Hoftheater für verschiedene Bevölkerungsschichten war: „Die Opernhäuser oder Haupttheater, besonders in größeren Städten, welche von Zuschauern mannigfaltiger Art besucht werden, müssen aber, um bestehen zu können, auf eine große Verschiedenheit der Entréepreise berechnet sein, damit ein Jeder nach seinen Umständen dort Platz finden kann, und ein bedeutender Unterschied zwischen den theuersten und billigsten Entréepreisen, mit gehörigen dazwischenliegenden Abstufungen ist hier nothwendig“, ebd., S. 219-220.

46 Vgl. zur Architektur von Theaterräumen ausführlich Meyer, Theaterbautheorien (Anm. 37), besonders S. 261-273 (Abschnitt „Das Raumprogramm“); Matthes, „Der allgemeinen Vereinigung gewidmet“ (Anm. 40), S. 136-195 (Kapitel „Der Innenraum des öffentlichen Theaters").

47 Ch. Wawra, Zwischen Repräsentation und Resignation. Um- und Neubaupläne des Württembergischen Hoftheaters Stuttgart 1750-1912 (Sammlungen des Württembergischen Landesmuseums Stuttgart), Stuttgart 1994, S. 52, zitiert nach Münzmay, Musikdramaturgie und Kulturtransfer (Anm. 13), S. 276. 
Bürgertums, was Münzmay auf ein „dezidiert exklusives, das ,einfache Volk ${ }^{6}$ ausschließendes (Selbst-)Verständnis gerade auch der um das Bürgertum erweiterten ,guten Gesellschaft ${ }^{\text {“" } 48}$ schließen lässt. Ähnliches war jedoch auch auf den unteren, teuren Logenrängen zu beobachten, wo sich Aristokratie und wohlhabendes Bürgertum begegneten und wo die Praxis, die Logen durch seitliche Trennwände und verschließbare Türen voneinander abzugrenzen, weit ins 19. Jahrhundert hinein Bestand hatte. Noch 1849 führte Gottfried Semper, Erbauer des 1841 eröffneten neuen Dresdner Hoftheaters, unter dem Eindruck der revolutionären Ereignisse „das separatistische Abschliessen der einzelnen Logen“ als eine unzeitgemäße „Folge unserer aristokratischen Einrichtungen" an. ${ }^{49}$

Die Beschaffenheit und räumliche Aufteilung eines Hoftheaters lässt darauf schließen, dass sich parallel zu den musikalischen Inszenierungen auf der Bühne auch soziale Inszenierungen im Zuschauerraum abspielten. Die heterogene Situation im Auditorium verwandelte Betrachter laut Müller in Akteure: „Opernaufführungen zu betrachten[,] heißt daher, der Inszenierung und Produktion sozialer Wirklichkeit beizuwohnen. " ${ }^{50}$ Gerade dem wohlhabenden Publikum diente der Opernbesuch dazu, Geschmack, Reichtum und Manieren zur Schau zu stellen und dadurch die bestehende politische und soziale Ordnung gewissermaßen zu legitimieren, wobei das Hauptanliegen der Zuschauer zunächst keineswegs der aufmerksamen Aufnahme des musikalischen Bühnengeschehens galt. Begünstigt durch die Tatsache, dass das Auditorium noch bis weit ins 19. Jahrhundert hinein auch während der Vorstellung hell erleuchtet blieb, war es durchaus üblich, dass Besucher später kamen oder früher gingen, im Zuschauerraum umherliefen, sich während der Vorstellung unterhielten und gegenseitig in den Logen besuchten, aßen und rauchten, Bekanntschaft mit Prostituierten machten und sich nur höchst selektiv auf die Musik konzentrierten..$^{51}$ Vor allem auf die prominenten Stellen der Partitur und die bekannten ,Highlights' reagierte das Publikum dann aber mit teilweise heftig sich artikulierender Zustimmung oder Ablehnung. Unruhen und lautstarke, gelegentlich gewaltsame Publikumsreaktionen bestimmten den Theateralltag des Vormärz, wobei diese, Müller zufolge, nicht nur aus spontanen Eingebungen resultierten, sondern als „oft bewusst zur Schau gestellte [...] Emotionen im Zuge von kulturellen Demonstrationen und politischen Deutungskämpfen " 52 angesehen werden können.

48 Ebd.

49 G. Semper, Das königliche Hoftheater zu Dresden, Braunschweig 1849, S. 8.

50 Müller, Distinktion, Demonstration und Disziplinierung (Anm. 4), S. 170.

51 Vgl. ebd., S. 174.

52 Ebd., S. 177. Mit der Rolle der Emotionalität des Publikums im Rahmen von Opernaufführungen beschäftigt sich auch eingehend R. Schlesinger, Die Emotionale Revolution. Die Oper als Schlüssel zu den 150 Jahren des 19. Jahrhunderts, Wien 2001; D. Fuhrimann, „Herzohren für die Tonkunst“. Opern- und Konzertpublikum in der deutschen Literatur des langen 19. Jahrhunderts (Rombach Wissenschaften / Reihe Litterae; 134), Freiburg/ Berlin 2005. 
Wie diese Beobachtungen zu distinktiven Verhaltensweisen des Opernpublikums zeigen, bedeutete die zunehmende Präsenz bürgerlicher Schichten nicht zugleich eine Verbürgerlichung des Hoftheaters im Sinne neuartiger, egalitärer Verhaltensmuster und -normen. Vielmehr übernahm das gehobene Bürgertum Verhaltensweisen des vormals rein aristokratischen Publikums, indem es das Theater als Raum der Unterhaltung und Selbstrepräsentation nutzte und sich innerhalb dieses Raums von niederen Publikumssegmenten abzugrenzen versuchte. Wo zuvor eine Hierarchisierung durch höfischen Rang stattfand, basierte sie nunmehr auf persönlichem Besitz. Dergestalt blieb die Funktion der Oper als Repräsentationsorgan trotz der Verbürgerlichung des Publikums und des Bruchs mit dem höfischen Wertesystem nach wie vor erhalten. ${ }^{53}$

Erst um die Jahrhundertmitte veränderte sich das Rezeptionsverhalten des deutschen Opernpublikums grundlegend durch Praktiken einer disziplinierten, schweigenden Aufnahme der Musik, die ihren Ausgangspunkt in den Konzerthäusern nahmen. Hier erfolgte in den 1820er und 1830er Jahren eine Aufwertung der Instrumentalmusik zu einer der höchsten Kunstformen, die eine prinzipielle Rezeptionshaltung der Andacht erforderte, wie sie von Vertretern der deutschen romantischen Bewegung um Ludwig Tieck und Wilhelm Heinrich Wackenroder beschrieben wurde. Infolgedessen schärfte sich auch im Bereich der Oper allmählich die Wahrnehmung des Kunstcharakters von Musik. Müller sieht in dem Wandel des Publikumsverhaltens den zunehmenden Einfluss des aufstrebenden Bürgertums, das „seinen Status durch die öffentliche Demonstration seines vorgeblich überlegenen Geschmacks" unterstrich und das schweigende, hingebungsvolle Hörverhalten als neue Praxis der „Idealisierung der Musik und bürgerlicher Selbstinszenierung" etablierte. ${ }^{54}$ Aber auch der Bau von neuen, immer größer werdenden Opernhäusern, die zunehmende Heterogenität des Opernpublikums und der daraus resultierende „Rückgang spontaner Affektausbrüche und Emotionen in der Öffentlichkeit als eine Form von wechselseitigem Selbstzwang "55 bestimmte dieses neue Publikumsverhalten. Die Aufführung der Oper rückte von der Peripherie einer das gesellschaftliche Spektakel im Zuschauerraum umrahmenden Unterhaltungsform zunehmend in den Mittelpunkt der Aufmerksamkeit, und mit ihr auch die in der Oper auftretenden Figuren bzw. die Sänger, die sie darstellten.

3.

Mit der zunehmenden Aufmerksamkeit und Bedeutung, die das Publikum Opern und ihren Inhalten im Laufe des 19. Jahrhunderts beimaß, vertiefte sich

53 Vgl. Walter, Distinktionsmerkmale des Opernpublikums (Anm. 30), S. 497.

54 Müller, Distinktion, Demonstration und Disziplinierung (Anm. 4), S. 179.

55 Ebd., S. 184-185. Müller beruft sich bei der Beschreibung der sich verstärkenden öffentlichen Selbstbeschränkung des Opern- und Konzertpublikums auf Norbert Elias' grundlegende Studie „Über den Prozeß der Zivilisation“ (erstmals erschienen 1939). 
im musikalischen Fachdiskurs auch die Diskussion um den Einfluss von Opern auf ihre Rezipienten. Hier trat Heinrich Heine prominent als einer der ersten Autoren hervor, die ein Wechselverhältnis von Oper und der revolutionären Gesellschaft der 1830er Jahre zu erkennen glaubten, wobei er Meyerbeer als einen der wichtigsten künstlerischen Wortführer dieser Zeit auserkor. Für Heine stellte der Zeitpunkt, an dem der deutsche Komponist mit der fulminanten Uraufführung seiner Grand Opéra „Robert le Diable“ 1831 in der Pariser Musikwelt erschien und das Publikum seither in Massen anzog, einen Wendepunkt in der Musikgeschichte dar, der mit einem Wendepunkt im politischen Bewusstsein der Gesellschaft des Vormärz korrelierte. So entfachte Heine 1837 während seines Pariser Exils die viel beachtete Melodie-Harmonie-Kontroverse im neunten der Briefe „Über die französische Bühne“ an seinen Freund August Lewald, in der er Meyerbeers Musik diejenige Rossinis vergleichend gegenüberstellte, um anhand der populärsten Repräsentanten zweier unterschiedlicher Opernstile den Paradigmenwechsel zu veranschaulichen. Nach Heines Ansicht war Rossini aufgrund des Melodienreichtums in seinen Opern als Anhänger des alten, restaurativen Systems anzusehen, während er in Meyerbeer aufgrund der vermeintlichen Vorherrschaft einer auf Zusammenklang und Harmonien, vor allem aber auf der Interaktion verschiedener gesellschaftlicher Gruppierungen gegründeten Musik den richtungweisenden Visionär des neuen, revolutionären Systems sah:

„Denn auf den Wogen Rossinischer Musik schaukeln sich am behaglichsten die individuellen Freuden und Leiden des Menschen; Liebe und Haß, Zärtlichkeit und Sehnsucht, Eifersucht und Schmollen, Alles ist hier das isolirte Gefühl eines Einzelnen; charakteristisch ist daher in der Musik Rossini's das Vorwalten der Melodie, welche immer der unmittelbare Ausdruck eines isolirten Empfindens ist. Bei Meyerbeer hingegen finden wir die Oberherrschaft der Harmonie; in dem Strome der harmonischen Massen verklingen, ja versäufen die Melodien, wie die besonderen Empfindungen des einzelnen Menschen untergehen in dem Gesammtgefühl eines ganzen Volkes, und in diese harmonischen Ströme stürzt sich gern eine Seele, die von den Leiden und Freuden des ganzen Menschengeschlechts erfaßt ist und Partei ergriffen hat für die großen Fragen der Gesellschaft. Meyerbeers Musik ist mehr social als individuell; die dankbare Gegenwart, die ihre inneren und äußeren Fehden, ihren Gemüthszwiespalt und ihren Willenskampf, ihre Noth und ihre Hoffnung in seiner Musik wieder findet, feiert ihre eigene Leidenschaft und Begeisterung, während sie dem großen Maestro applaudirt. “56

Heine verortete die Musik der beiden Komponisten somit in zwei unterschiedlichen politischen Zeiträumen. Rossinis Musik war für ihn ,angemessener für die Zeit der Restauration, wo, nach großen Kämpfen und Enttäuschungen, bei dem blasirten Menschen der Sinn für ihre großen Gesammtinteressen in den Hinter-

56 H. Heine, Über die französische Bühne. Vertraute Briefe an August Lewald. Neunter Brief, in: Allgemeine Theater-Revue 3 [Stuttgart und Tübingen], 1837, S. 220-235, hier S. 223. Bezeichnenderweise klammert Heine Rossinis für die Pariser Opéra komponierten Werke, namentlich seinen „Guillaume Tell“, in dem Rossini sich stilistisch wohl am weitesten von seinen großen Belcanto-Opern der 1810er und 1820er Jahre entfernt hatte, aus diesen Betrachtungen aus. 
grund zurückweichen mußte“. ${ }^{57}$ In der gegenwärtigen Zeit hingegen, die geprägt war von den Ereignissen und Nachwirkungen der Julirevolution, wie Heine sie in den 1830er Jahren während seines Pariser Exils wahrnahm, haben die Menschen „weder Muße noch hinlängliche Seelenruhe, um sich an den Melodien des Privatgefühls zu ergötzen, und nur wenn die großen Chöre von Robert le Diable oder gar der Hugenotten harmonisch grollen, [...] horchen ihre Herzen, und schluchzen, jauchzen und grollen im begeisterten Einklang ${ }^{\text {" }}{ }^{58}$ Für Heine war Meyerbeer demnach der Mann seiner Zeit, der das „Privatgefühl“ zugunsten der gesellschaftlich-revolutionären Ideen der Gegenwart überwunden hat. So glaubte Heine, in den Opern Meyerbeers das musikalische Sprachrohr unterdrückter Volksschichten und eine ideale Ausdrucksform des aufkeimenden Liberalismus zu erkennen. Mit Meyerbeer hat die Oper für Heine den Platz in der Mitte einer Gesellschaft eingenommen, deren liberales Bestreben nach politischer Veränderung im Medium der Musik gespiegelt wurde..$^{59}$

Im deutschen Kulturraum hingegen, wo Opern französischer und italienischer Provenienz weitaus konstanter und in größerer Zahl auf den Theaterspielplänen vertreten waren als deutsche Opern, begegneten vor allem jene Autoren der Popularität Meyerbeers mit großer Skepsis, die sich im Umfeld aufkeimender deutsch-nationaler, frankophober Strömungen für die Etablierung einer deutschen Nationaloper aussprachen. Dabei warf man dem Komponisten vor, sich mit einem Übermaß an spektakulären Bühneneffekten und mitreißenden Massenszenen sowie dem Ausreizen sämtlicher musikalischer Mittel der Schaulust des Pariser Publikums anzubiedern. So unterstellte ihm etwa Robert Schumann, Gründer der deutsch-national ausgerichteten „Neuen Zeitschrift für Musik“, in einer radikalen Kritik an Meyerbeers „Les Huguenots“ ein Handeln nach reinem Erfolgskalkül: „Verblüffen oder kitzeln ist Meyerbeers höchster Wahlspruch“, 60 weshalb seine Oper „das Gesammtverzeichniß aller Gebrechen und der einigen wenigen Vorzüge seiner Zeit" darstelle und auf nichts anderes abziele als den „kleine[n] Beifall der Gegenwart“. ${ }^{61}$ Ähnlich urteilte die Schriftstellerin Jeanette

57 Ebd.

58 Ebd., S. 224.

59 Heines Anschauungen über die Musik Meyerbeers sind jedoch nur vor dem Hintergrund zu verstehen, dass er, nachdem seine politischen Schriften Ende des Jahres 1835 per Dekret des deutschen Bundestags verboten worden waren, auf das Gebiet des Musikjournalismus ausweichen und somit „in den unverfänglichsten, von allen Tagesfragen entferntesten Winkel seiner ihm durch die Umstände aufgenötigten [...] ästhetisch-kritischen Produktion“ flüchten musste, M. Mann, Heinrich Heines Musikkritiken (Heine-Studien), Hamburg 1971, S. 29. So hat er seine Ansichten über die politischen Umstände seiner Zeit nurmehr in der verschlüsselten Form von musikästhetischen Beobachtungen äußern können.

60 R. Schumann, Fragmente aus Leipzig 4, in: Neue Zeitschrift für Musik [Leipzig], Bd. 7, Nr. 19, 5. September 1837, S. 73-75, hier S. 74, Sp. 1.

61 Ebd., S. 75, Sp. 2. Vgl. zu Schumanns Rezension ausführlich M. Walter, „Man überlege sich nur Alles, sehe, wo Alles hinausläuft!“ Zu Robert Schumanns ,Hugenotten'-Rezension, in: Die Musikforschung 36, Heft 3, 1983, S. 127-144. 
von Haza in ihrer Kritik an derselben Oper, indem sie bemängelte, dass das deutsche Publikum dem „absurde[n], krassen und obscönen Theatermischmasch" 62 der Oper ausgesetzt sei, und forderte, „dass man daher, wegen des Schadens, der dadurch für die ungebildeten Zuschauer entstehen kann, sie ohne Gnade von der Bühne verbannen sollte“. 63

Wie Heine sah auch Haza in der Musik Meyerbeers eine wesentliche Erscheinungs- und Ausdrucksform einer neuen, von der Öffentlichkeit bestimmten Zeit, was sie jedoch im Gegensatz zu Heine als Gefahr für die Entfaltung individueller Interessen bewertete. So lehnte sie in geradezu biederer Haltung die politischen Entwicklungen ihrer Zeit ab, in der "die Oeffentlichkeit an der Tagesordnung und die ,Berwegung die erste Bürgerpflicht ist, seitdem wir selber Regenten geworden, und über der Sorge für die Familien Andrer, unsre eigne vernachlässigen" ". ${ }^{64}$ Die politischen Entwicklungen ihrer Zeit sah sie in den Opern Meyerbeers und seiner Pariser Komponistenkollegen, die stets revolutionäre, kriegerische oder religiöse Konflikte der Vergangenheit thematisierten, gleichsam auf der Bühne gespiegelt und somit unumwunden mit ihnen verknüpft: „,...] seitdem müssen wir in der Stummen von Portici, den Hugenotten, und allen möglichen furiosen Opern, in Blutströmen waten bis ans Knie, um öffentliches Wesen und öffentlichen Zwist zu lernen". ${ }^{65}$ Das Pariser Repertoire symbolisierte so für die Autorin einen Wendepunkt, von dem aus der Rückzug der Gesellschaft ins Private und Häusliche nicht mehr möglich war und an dem sich eine neue, politische Öffentlichkeit konstituiert hatte.

Die französische Grand Opéra, deren Hauptvertreter Meyerbeer und ihre Rolle im Fachdiskurs des deutschsprachigen Musikschrifttums zeigen auf exemplarische Weise, wie sich sowohl Inhalte als auch Wahrnehmungsformen von Opern in der ersten Hälfte des 19. Jahrhunderts veränderten. Indem die Werke neuartige Stoffe, Figuren und Konflikte präsentierten, die von den Ereignissen der jüngeren Geschichte und der romantischen Literatur Walter Scotts und Victor Hugos inspiriert waren, boten sie dem um bürgerliche Schichten erweiterten Publikum neuartige Möglichkeiten der Identifikation. Ähnlich wie auch die von romantischen Strömungen beeinflussten italienischen Opern Vincenzo Bellinis, Gaetano Donizettis und vor allem Giuseppe Verdis sowie auch die frühen Opern Richard Wagners evozierte die Grand Opéra, eingekleidet in Sujets der jüngeren Vergangenheit und visualisiert durch detailgetreue Bühnenbilder und nachgebaute Originalschauplätze, das scheinbar authentische Kolorit vergangener Epochen. ${ }^{66}$ In dieser Form

62 H. Paris [Pseud. J. von Haza], Einige deutsche Gedanken bei Gelegenheit einer französischen Oper. Von einem Laien, in: Cäcilia, eine Zeitschrift für die musikalische Welt [Mainz], Bd. 20, 1839, S. 1-51, hier S. 8.

64 Ebd., S. 44 (Hervorhebungen im Original).

65 Ebd. (Hervorhebungen im Original).

66 Die Inszenierung und Bedeutung von Geschichte bildet einen zentralen Untersuchungsgegenstand in englischsprachigen Publikationen zur Grand Opéra; vgl. etwa die Studien von 
nahm die Bühnenhandlung, so Walter, „Bezug auf die Lebenserfahrungen des neuen, bürgerlichen Publikums, nicht mehr auf die Bildungserfahrungen der alten Aristokratie“ ${ }^{67}$ Diese neuen Lebenserfahrungen waren vor allem geprägt von den rasanten Entwicklungen in Großstädten wie Paris, ihren Kontrasten und politischen Umbrüchen, ihren diversen gesellschaftlichen Gruppierungen, die gemeinsam an den Unterhaltungsangeboten partizipierten, und dem daraus resultierenden „Konflikt zwischen den Ängsten und Hoffnungen einzelner Individuen und der unaufhaltsamen Dynamik von unkontrollierten Massenprozessen“. ${ }^{68}$ Auf solchen Kontrasten basierte denn auch, mit Gerhard, der zentrale dramaturgische Konflikt der Grand Opéra, indem sie „unter dem Druck neuer Wahrnehmungszumutungen schrittweise neue Anschauungsformen ausprägte “. .69

Vor dem Hintergrund, dass also die Grand Opéra sowie die mit ihr verwandten Gattungen aus dem italienischen und deutschen Raum künstlerische Plattformen bildeten, auf denen gesellschaftliche Entwicklungen verhandelt, neue Wahrnehmungsformen dargeboten und Identifikationspotenziale bereitgestellt wurden, prägte sich auch ein neuer Heldentypus aus, der durch innere Haltung und äußere Handlung Vorbildfunktionen für das neue Publikum bereithielt und Wertvorstellungen (re)präsentierte. In dem Maße, in dem die Institution der Oper zunehmend ihre Funktion als exklusives Repräsentationsorgan herrschender Eliten verlor und auch das bürgerliche Publikum in den Kreis der durch das Bühnengeschehen und Bühnenpersonal Adressierten hinzutrat, verschwanden zunehmend die antiken und mythischen Heldenfiguren des barocken und klassischen Musiktheaters, spiegelten diese in ihrer Unantastbarkeit und Unfehlbarkeit doch vor allem die Exzeptionalität realer Herrscher wider. An ihre Stelle traten psychologisch konturierte Menschen unterschiedlichster sozialer Herkunft, die in der realen, nach-antiken Geschichte verortet waren und durch deren Vermögen zu Liebe, Leid und Kampf Handlungsräume aufgezeigt wurden, innerhalb derer das Verhältnis von Individuen zu gesellschaftlichen Umwälzungen und zu sozialer und politischer Ungerechtigkeit ausgelotet wurde. Die Verstrickung des Helden in eine politische oder religiöse, meist in der realen Geschichte verankerten Revolte, die anzuführen er durch die Unterstützung seiner Anhängerschaft auserkoren ist, gehört zu den dramaturgischen Hauptcharakteristika des Rollenprofils von Heldenfiguren.

S. Hibberd, French Grand Opera and Historical Imagination, Cambridge 2009; M. A. Pottinger, The Staging of History in France. The Characterization of Historical Figures in French Grand Opéra during the Reign of Louis-Philippe, Saarbrücken 2009; C. Newark, Staging Grand Opéra. History and the Imagination in Nineteenth-Century Paris, Oxford 1999 sowie S. Williams, The Spectacle of the Past in Grand Opera, in: D. Charlton (Hrsg.), Cambridge Companion to Grand Opera, Cambridge 2003, S. 58-75.

Walter, „Die Oper ist ein Irrenhaus“ (Anm. 8), S. 56.

68 A. Gerhard, Grand Opéra, in: Die Musik in Geschichte und Gegenwart 2, Sachteil, Bd. 3, Kassel [u.a.] 1995, Sp. 1575-1595, hier Sp. 1582.

69 Gerhard, Die Verstädterung der Oper (Anm. 8), S. 51. 
So führt etwa Raoul in Meyerbeers „Les Huguenots“ in der sogenannten Bartholomäusnacht 1572 die Hugenotten im Kampf gegen die Katholiken an, Arnold ruft in Rossinis „Guillaume Tell“ die schweizer Verbündeten zum Unabhängigkeitskampf gegen die habsburgische Fremdherrschaft um 1300 auf, Masaniello in Aubers „La Muette de Portici“ ist Anführer eines neapolitanischen Fischeraufstandes im Jahre 1647, und Arrigo beteiligt sich in Verdis Risorgimento-Oper „La battaglia di Legnano" am Kampf der Norditaliener gegen Friedrich I. Barbarossa im 12. Jahrhundert. Auch real existierende Personen finden sich in einigen Opern als Heldenfiguren wieder: Cola di Rienzo (1313-1354) etwa versucht in Wagners „Rienzi“ als Volkstribun die politische Ordnung in Rom wiederherzustellen, und Jan van Leiden (1509-1536) führt in Meyerbeers „Le Prophète“ als Jean de Leyde die niederländische Wiedertäuferbewegung an. Emotional gestärkt oder auch ins Schwanken gebracht durch die Liebe zu einer Frau finden diese und viele andere Heldenfiguren mit ähnlicher Agenda am Ende tragischer Final- und Kampfszenen den Tod. Dabei lassen sie sich gerade in ihrem Scheitern dem Typus romantischtragischer Helden zuordnen, wie sie auch in der Literatur und im Theater dieser Zeit vorkommen.

Die Verbindung von Oper und Gesellschaft liegt auf dieser Ebene der dramaturgischen Gestaltung der Heldenfiguren darin, dass hier viele auf die Moderne vorausweisende Fragen nach dem Verhältnis von Individuum und Gemeinschaft permanent evoziert und sowohl Chancen als auch Bedrohungen aufgezeigt werden, die die in Form von Chören omnipräsente Masse für die Freiheit des Einzelnen darstellt. ${ }^{70}$ Weil diese Masse sich in den Werken gleich einer ,Interpretationsgemeinschaft ${ }^{`}$ zum Einzelnen, der Heldenfigur, in Beziehung setzt, seinem Handeln zustimmend oder ablehnend gegenübertritt und auf die meist vom Helden ausgelöste Konfliktsituation aktiv reagiert, bot sie dem Zuschauer die Möglichkeit, die dargestellten Konflikte im imaginären Raum des Musiktheaters nachzuvollziehen, sich sowohl mit der Masse zu identifizieren als auch zum Konflikt des Helden zu positionieren und auf das Bühnengeschehen aktiv - etwa durch Mitsingen, Zischen oder andere Bekundungen des Beifalls oder Missfallens - einzuwirken. ${ }^{71}$

$\mathrm{Zu}$ dieser Erschaffung einer gewissermaßen lebendigen Illusion im Raum des Theaters trug aber nicht nur die dramatische Situation und die Präsenz einer Heldenfigur und seiner Gemeinschaft auf der Bühne bei, sondern auch der einzelne

70 So bemerkt auch Simon Williams: „, [I]t is possible to see the work of Auber, Halévy and Meyerbeer a first instance of one of the most persistent conflicts in modern drama, that of the individual pitted against the forces of an impersonal society, which has little concern for the integrity of freedom of human beings", Williams, The Spectacle of the Past in Grand Opera (Anm. 66), S. 74.

71 Die besonders im italienischen Raum heftig sich artikulierenden Publikumsreaktionen und die Vereinnahmung von Verdis frühen Opern für politische Deutungen beschreibt eingehend P. Stamatov, Interpretative Activism and the Political Uses of Verdi's Operas in the 1840s, in: American Sociological Review 67, Heft 3, 2002, S. 345-366. 
Sänger durch seine Fähigkeit, sich in der Bühnensituation vokal zu artikulieren. Nachdem das Heldenfach ab den 1820er Jahren von Tenorsängern dominiert wurde, wandelte sich die Ästhetik des virtuosen Gesangs in extrem hoher Stimmlage, wie sie vor allem durch die italienischen Kastratensänger des 18. Jahrhunderts etabliert und im Zuge einer Übernahme von männlichen Heldenrollen durch Frauenstimmen im frühen 19. Jahrhundert fortgeführt wurde, ${ }^{72}$ zunehmend in Richtung einer auf Durchschlagskraft und Dramatik ausgerichteten vokalen Präsentation des Helden. Indem Gesang und Darstellung mehr und mehr in eine funktionale Einheit traten, konnten sich die seelische Tiefe und der innere und äußere Konfliktreichtum der Heldenfiguren artikulieren. Dabei galt die Fähigkeit eines Sängers, kraft seiner Stimme und seines Ausdrucks die psychische und emotionale Konfliktsituation der von ihm dargestellten Figur äußern und für den Zuhörer nachvollziehbar machen zu können, als ein zentrales Bewertungskriterium seines Gesangs. So bewunderte man 1823 etwa an dem international renommierten Tenorsänger Domenico Donzelli in seiner Paraderolle des Rossinischen Otello „die Steigerung, mit welcher er die in seiner Brust auflodernde Leidenschaft so lebendig vor unsern Augen [...] zu entfalten wusste, dass die Macht der Täuschung ihre ganze Gewalt auf die Zuschauer ausübte". ${ }^{73}$ Der im deutschen Raum hochgefeierte Tenor Joseph Tichatschek überzeugte wiederum 1847 als Interpret der Heldenpartie des Raoul in Meyerbeers „Les Huguenots“, „wo er das Heldenthum, mit welchem Raoul gegen das gewaltige Schicksal kämpfen muss, das auf seinen jugendlichen Schultern lastet, in feuriger Kraft vertrat" und dadurch einen nicht enden wollenden „Beifall- und Hervorruf“ auslöste. ${ }^{74}$

Wie sich zeigt, entstanden innerhalb des Opernpublikums in der ersten Hälfte des 19. Jahrhunderts neue Wahrnehmungszusammenhänge, die wiederum mit neuen Artikulations- und Darstellungsformen von Heldenfiguren und den sie umgebenden Gemeinschaften auf der Bühne korrelierten. Indem Opern dem um bürgerliche Schichten erweiterten Publikum durch Gesang und Darstellung neuartige Identifikationsmöglichkeiten boten, wandelten sie sich von einem Ort, an dem die aufmerksame Werkrezeption vor dem Hintergrund der Herausstellung, Demonstration und Kultivierung unterschiedlicher sozialer Praktiken eine nachrangige Rolle spielte, zu einem Ereignis, bei dem sich Realität und Illusion

72 Vgl. zu der Übergangszeit, in der die vormals von Kastratensängern verkörperten Opernhelden zunehmend durch Sängerinnen abgelöst wurden, N. A. André, Voicing Gender. Castrati, Travesti, and the Second Woman in Early-Nineteenth-Century Italian Opera, Bloomington, IN 2006 sowie Th. Seedorf, Heldensoprane. Die Stimmen der eroi in der italienischen Oper zwischen 1600 und 1840 (Figurationen des Heroischen; 1), Göttingen 2015.

73

Rezension über eine Aufführung des „Otello“ 1823 am Wiener Kärntnertortheater in: Allgemeine musikalische Zeitung, mit besonderer Rücksicht auf den österreichischen Kaiserstaat [Wien], Jg. 7, Nr. 76, 20. September 1823, S. 602, Sp. 2.

74 Rezension über eine Aufführung der „Hugenotten“ 1847 an der Berliner Hofoper in: Neue Berliner Musikzeitung [Berlin], Jg. 1, Nr. 10, 10. März 1847, S. 87. 
durchdringen konnten. Oper und Gesellschaft waren somit in der ersten Hälfte des 19. Jahrhunderts vor allem in der politisch gefärbten Wahrnehmung ihrer Beobachter in ein neuartiges Wechselverhältnis getreten. 
